\title{
NECESIDAD-ESENCIALIDAD DE CRITERIOS LEGALES PARA LA DETERMINACIÓN DE UNA SANCIÓN ADMINISTRATIVA
}

\author{
THE NEED FOR LEGAL STANDARDS WHEN ESTABLISHING AN \\ ADMINISTRATIVE PENALTY
}

Rosa Fernanda Gómez GonZÁlez*

\begin{abstract}
RESUMEN: Se comenta la sentencia Rol No 2.922-2015, del Tribunal Constitucional, que declara inaplicable el inciso primero del artículo 29 del Decreto Ley No 3.538, de 1980, por carecer de criterios para determinar la sanción de multa en el caso específico. El trabajo analiza la necesidad-esencialidad de que la norma recurrida, otorgue criterios para la aplicación de multas y busca establecer si su estructura actual efectivamente configura un conflicto de constitucionalidad.
\end{abstract}

Palabras clave: Discrecionalidad, potestad sancionadora, criterios de determinación

ABSTRACT: The ruling of the Tribunal Constitucional Rol No 2922-2015, that declares inapplicable the first paragraph of the article 29 from the Law Decree No. 3,538 of 1980 is studied since it lacks enough criteria to determine the penalty of a fine. The paper analyzes the need, or even the essentiality that the appealed precept grants legal standards for determining fines. It also seeks to establish whether its current structure generates a constitutional conflict.

Keywords: Discretionality, sanctioning power, determination criteria

\section{INTRODUCCIÓN}

Nuestro actual régimen administrativo sancionador es resultado de una progresiva proliferación de disposiciones represivas que se han incorporado al ordenamiento jurídico en paralelo a una construcción doctrinal y jurisprudencial que básicamente ha buscado precisar sus contornos y límites.

Uno de los pronunciamientos más relevantes sobre la materia es la sentencia Rol No 244, de $1996^{1}$, en la que el Tribunal Constitucional señaló que "los principios inspiradores del orden penal contemplados en la Constitución han de aplicarse, por regla general, al

\footnotetext{
Abogada, Magíster en Derecho Regulatorio UC. Candidata a doctora en Derecho por la Pontificia Universidad Católica de Valparaíso. Dirección postal: Avenida Brasil 2950, Valparaíso, Chile, CP 2580085. Dirección electrónica: rsgomez@uc.cl. Beneficiaria Beca CONICYT-PCHA/Doctorado Nacional/2016-Folio No 21160419.

Honorable Camara de Diputados (1996). Proyecto de ley que modifica la ley No 4.601, Ley de Caza, a fin de proteger la fauna, Rol No 244-96.
} 
derecho administrativo sancionador, puesto que ambos son manifestaciones del ius puniendi propio del Estado".

Bajo tal predicamento, tanto el Derecho Penal como el Derecho Administrativo Sancionador tienen su origen en un Derecho punitivo estatal único, situado por encima de estos, que los alimenta de sus principios y restricciones ${ }^{2}$. En virtud de este origen común, surge la habilitación para aplicar "con matices" los principios constitucionales del orden penal al Derecho Administrativo Sancionador, con lo cual se buscó establecer, conforme al marco del Estado de Derecho, un conjunto de garantías para los particulares.

Más de veinte años han transcurrido desde aquella jurisprudencia, la cual ha sido replicada en innumerables fallos judiciales ${ }^{3}$ y en otros tantos pronunciamientos de Contraloría General de la República ${ }^{4}$, sin que se haya avanzado lo suficiente en fijar concretamente el estatuto jurídico y el contenido de este poder represivo superior, aunque ciertos contornos se han ido definiendo paulatinamente por la jurisprudencia, de diverso orden, la cual ha otorgado algunas soluciones, por ejemplo en materia de prescripción, tipicidad, transmisibilidad de las multas, non bis in idem, solve et repete, entre otros.

Por su parte, los primeros trabajos doctrinales de administrativistas nacionales sobre la materia datan de comienzos de la década de 1980, y en ellos se analizan básicamente los problemas de constitucionalidad de la potestad5. Una dogmática de "segunda generación" (posterior a la STC Rol No 244 y que da por superado el conflicto de constitucionalidad) busca explicar sus alcances, límites y las diferencias y/o semejanzas que existirían con el Derecho Penal, así como los matices a los cuales estarían sujetos los principios extrapolados desde este ámbito a las facultades represivas de la Administración.

Ahora bien, uno de los aspectos escasamente investigados en materia de Derecho Administrativo Sancionador dice relación con el grado de discrecionalidad que existe en este ámbito. En concreto, no está claro cuáles son los límites que debe observar su ejercicio, sobre todo en aquella instancia en que la autoridad debe determinar el tipo de sanción aplicable y la intensidad de la misma.

Por ello, este comentario pretende evaluar las razones sostenidas por el Tribunal Constitucional al resolver la inaplicabilidad del inciso primero del artículo 29 del Decreto Ley No 3.538, de 1980, que crea la Superintendencia de Valores y Seguros (SVS), en el marco del juicio seguido bajo el Rol No 2922-2015, por Roberto Guzmán Lyon para impugnar las sanciones impuestas por dicha entidad en el contexto del denominado "Caso Cascada”.

\footnotetext{
Sin perjuicio de lo discutible que pueda resultar esta doctrina. En tal sentido, Román sostiene que el fundamento relativo a la existencia de un único ius puniendi estatal sería una ficción, que de ser efectiva el Derecho Penal y el Administrativo Sancionador debieran ser informados por los principios del Derecho Público Punitivo del Estado, en RomÁn (2010) p.162. Recientemente, esta teoría también ha sido criticada por Raúl Letelier.

3 Cúneo y otros con Superintendencia de VAlores y Seguros (2015); Constructora Isla Grande Limitada

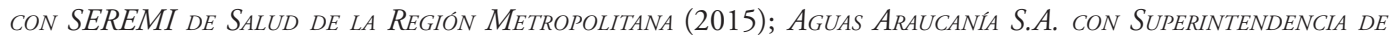
SERVICIOS SANITARIOS (2016); FARAH CON SUPERINTENDENCIA DE VALORES Y SEGUROS (2016), entre otros.

4 Dictámenes Nos. 16.157 (2014); 60.341 (2013); 13.790 (2013); 63.697 (2011); 22.483 (2011); 34.407 (2008); 31.239 (2005); 14.571 (2005), entre otros.

5 Soto (1979/1980), Aróstica (1987a), Aróstica (1987b) y Aróstica (1988).
} 
Para ello se revisarán las argumentaciones del Tribunal Constitucional (I), los comentarios que se efectúan a dicha sentencia (II), para luego establecer la necesidad-esencialidad de la configuración legal de criterios para determinar una medida represiva de multa (III), culminado el comentario con algunas conclusiones.

\section{LA SENTENCIA ROL No 2922-2015, DEL TRIBUNAL CONSTITUCIONAL ${ }^{6}$}

\section{GESTIÓN INVOCADA}

Se trata de la reclamación judicial de la multa impuesta a Roberto Guzmán Lyon, mediante la Resolución Exenta No 223, de 2014, de la SVS, correspondiente a 550 mil UF por contravención a la Ley No 18.045, sobre Mercado de Valores. La infracción consistió en la participación del sancionado en un "esquema" de inversión y financiamiento mediante un conjunto de transacciones bursátiles calificadas como ilícitas por el regulador.

\section{Conflicto de COnSTitucionalidad}

La norma impugnada afectaría, básicamente, los principios de legalidad y proporcionalidad, por cuanto carecería de estándares de certeza, determinación y especificidad, ya que no dispone de criterios, parámetros o principios que permitan determinar el quantum de la sanción aplicable al caso concreto, por lo que dicho proceso quedaría entregado al mero arbitrio de la autoridad.

\section{AnÁlisis efectuado por el Tribunal Constitucional}

\subsection{Sobre los principios de igualdad ante la ley y debido proceso}

El Tribunal sostiene, en síntesis, que la igualdad ante la ley importa que las normas sean iguales para todas las personas que se encuentren en las mismas circunstancias, lo cual supone una diferenciación razonable y objetiva entre quienes no estén en esa condición, por lo que el legislador puede establecer regímenes especiales en la medida que ello no sea arbitrario. Por ello, es necesario efectuar un examen de razonabilidad y de proporcionalidad de la distinción, el cual considere los hechos, el fin de la ley y los derechos afectados.

Agrega que el derecho a un proceso previo, legalmente tramitado, racional y justo contempla las garantías de "publicidad de los actos jurisdiccionales, el derecho a la acción, el oportuno conocimiento de ella por la parte contraria, el emplazamiento, la adecuada defensa y asesoría con abogados, la producción libre de pruebas conforme a la ley, el examen y objeción de la evidencia rendida, la bilateralidad de la audiencia y la facultad de interponer recursos para revisar las sentencias motivadas dictadas por tribunales inferiores" (parte final del considerando 18).

Roberto GuZMÁn LYON CON Superintendencia de VALORES Y SEGURos (2016). Artículo 29 del Decreto Ley No 3.538, de 1980, Ley Orgánica de la Superintendencia de Valores y Seguros, Rol No 2922-2015. 


\subsection{El principio de proporcionalidad}

El Tribunal destaca la necesaria relación de equilibrio que debe existir entre el castigo impuesto y la conducta imputada. Agrega que, si bien la Constitución no recoge explícitamente el principio, este se encuentra integrado dentro de los principios inherentes al Estado de Derecho (artículos $6^{\circ}$ y 70), en la prohibición de conductas arbitrarias (artículo 19, No 2), en la garantía normativa del contenido esencial de los derechos (artículo 19, № 26), en la garantía del debido proceso (artículo 19 No 3), entre otros preceptos de los cuales se puede inferir.

Luego, señala que conforme al principio de predeterminación normativa debe existir una correspondencia entre la conducta ilícita tipificada y la sanción consiguiente. Para ello, el legislador ha debido otorgar a los órganos dotados de ius puniendi de ciertas directrices objetivas y de obligatoria consideración para efectos de ponderar la sanción. Afirma que la omisión de este deber por parte del legislador vulnera el principio de proporcionalidad (considerando 27).

\subsection{La falta de motivación}

El Tribunal indica que la proporcionalidad exige una debida motivación no solo de la decisión de sancionar sino también justificar el quantum, monto o entidad de la medida represiva. Es preciso explicitar el vínculo racional que existe entre la infracción y la sanción y que la medida adoptada se ajusta, en definitiva, a los fines legítimamente perseguidos por el ordenamiento jurídico. Esta explicación de motivos permite controlar la discrecionalidad administrativa y justificar, eventualmente, un cambio de doctrina atendida la naturaleza y características de la infracción cometida o de acuerdo a las necesidades impuestas por el interés público ${ }^{7}$.

El Tribunal advierte que el problema de constitucionalidad observado tiene su origen en la ausencia de parámetros en el artículo 29 que permitan fundar la decisión adoptada, ello al margen de lo que se pudiese sostener acerca de la pertinencia de la multa. En otras palabras, la autoridad administrativa es competente para aplicar, de modo discrecional, la sanción asociada a cada infracción dentro del conjunto de medidas fijadas, en la medida que disponga de algún estándar que guíe la determinación de la misma.

\subsection{La resolución del Tribunal Constitucional}

El razonamiento utilizado por el Tribunal para acoger la acción de inaplicabilidad contra el precepto impugnado, considera que la norma recurrida no contiene ningún parámetro de "objetividad" para la determinación de la sanción de multa, por lo que su aplicación en el caso concreto produce efectos contrarios a la Carta Fundamental vulnerando específicamente el principio de proporcionalidad, concreción de la igualdad ante la ley y la

Esto no habría ocurrido en el caso sub lite según queda de manifiesto de la lectura del considerando cuadragésimo sexto: “(...) la Resolución 223, de 2 de septiembre de 2014, que aplica la sanción de multa, invocando en los "vistos" el artículo 29 cuestionado, es escueta al momento de fundamentar su aplicación en el caso concreto./ En efecto, en el considerando 1621 se alude en términos generales a que las multas deben tener siempre el carácter de "proporcionales y corresponderse con los tipos y conductas infraccionales cometidas por cada formulado de cargos".”. 
prohibición de discriminación arbitraria (artículo 19, $\mathrm{N}^{\circ}$ 2) y el derecho a un justo y racional y debido proceso administrativo (artículo 19, $\mathrm{N}^{\circ} 3$ ); desde que se hace una mera remisión, también general y no motivada, a lo dispuesto en los artículos 27 y 28 del aludido Decreto Ley No 3.538, de 1980.

El Tribunal enfatiza que, en el caso concreto, los efectos contrarios a la Constitución, lo son en específico "al principio de proporcionalidad, desde que su materialización fáctica no se sustenta sobre la base de criterios de razonabilidad (objetivos y ponderados) que permitan determinar por qué se ha impuesto una determinada sanción, e incluso, por qué un porcentaje específico y no otro.”. Agrega que la disposición impugnada impone una potestad discrecional arbitraria que "no se compadece con las exigencias mínimas de un Estado de Derecho, que permitan fundamentar la decisión y, luego de una detallada subsunción de los hechos al derecho, señalar de manera lógica y precisa cuál es la razón del quantum de la sanción, cumpliendo así con los presupuestos de un debido proceso administrativo" (considerando 49) ${ }^{8}$.

\section{COMENTARIOS A LA SENTENCIA}

Un sistema represivo ideal es aquel que, entre otras particularidades, configura detalladamente las acciones $\mathrm{u}$ omisiones infraccionales, sus consecuentes sanciones y los parámetros o criterios necesarios para su aplicación. Sin embargo, dadas las matizaciones de que es objeto el Derecho Administrativo Sancionador existe un menor grado de densidad y precisión normativa, lo que conlleva, consecuencialmente, a la existencia de diversos niveles de discrecionalidad (fuerte o débil).

\section{Acerca de la existencia de una "potestad discrecional arbitraria”}

Está fuertemente arraigado en la conciencia jurídica nacional la idea de que la potestad sancionadora de la Administración no puede admitir espacios de discrecionalidad", toda vez que se trataría de poderes que importan una significativa restricción a los derechos de los sujetos regulados.

\footnotetext{
8 El criterio contenido en este fallo ha sido posteriormente reiterado en MANUEL BULNES MUZARD Y FELIPE ERRÁzuriz Amenábar con Superintendencia de VAlores y Seguros (2017). Artículo 29 del Decreto Ley $\mathrm{N}^{\circ}$ 3.538, de 1980, Ley Orgánica de la Superintendencia de Valores y Seguros, Rol No 3014-2016; JULIO PONCE LEROU CON SuperintendenCIA de VAlores y Seguros (2018). Artículo 29 del Decreto Ley $\mathrm{N}^{\circ} 3.538$, de 1980, Ley Orgánica de la Superintendencia de Valores y Seguros, Rol N³236-2016; LEONIDAS VIAL ECHEVERRÍA CON Superintendencia de VAlores y Seguros (2018). Artículo 29 del Decreto Ley № 3.538, de 1980, Ley Orgánica de la Superintendencia de Valores y Seguros, Rol No 3684-2017; Alberto Le BLANC Matthei Con SuperinTENDENCIA DE VALORES Y SEGUROS (2018). Artículo 29 del Decreto Ley No 3.538, de 1980, Ley Orgánica de la Superintendencia de Valores y Seguros, Rol No 3542-2017 y LARRAÍN VIAL S.A. CON SUPERINTENDENCIA DE VALORES Y SEGUROS (2018). Artículo 29 del Decreto Ley Nº 3.538, de 1980, Ley Orgánica de la Superintendencia de Valores y Seguros, Rol No 3575-2017.

9 Por ejemplo, así lo ha sostenido Olga Feliú respecto del caso comentado. Véase: http://www.latercera.com/ noticia/negocios/2016/10/655-699361-9-olga-feliu-abogada-el-superintendente-tiene-una-potestad-que-no-esdiscrecional.shtml
} 
Sin embargo, la existencia de discrecionalidad en este ámbito no la constituye per se en una "potestad arbitraria" ${ }^{10}$, como lo indica el Tribunal, por el contrario, la configuración discrecional del poder represivo permite que la autoridad pueda "ajustar" el ejercicio de ese poder a las particulares circunstancias que rodean la situación fáctica que debe resolver. En otras palabras, es precisamente la discrecionalidad la que permite al órgano administrativo ejercer razonable y proporcionalmente sus atribuciones represivas.

Ciertamente la entrega por parte del legislador de criterios, estándares, factores, marcos, límites, parámetros, directrices, barómetros o cualquiera sea la denominación que se les otorgue, constituye una significativa guía orientativa para la determinación de sanciones y su quantum, pero ello no importa que sean exclusivas y excluyentes de otros parámetros o consideraciones que pueda tener a la vista la autoridad ni que su ausencia irrogue una inconstitucionalidad per se.

\section{LA DisCRECIONALIDAD OBJETADA A LA SUPERINTENDENCIA}

El precepto reclamado es el inciso primero del artículo 29 del Decreto Ley No 3.538, de 1980, que crea la SVS, el cual precisa que "No obstante lo expresado en los artículos 27 y 28 al aplicar una multa, la Superintendencia, a su elección, podrá fijar su monto de acuerdo a los límites en ellos establecidos o hasta en un 30\% del valor de la emisión u operación irregular.", siendo esta última parte la cuestionada constitucionalmente.

Como se podrá advertir, el legislador le otorgó a la SVS un poder discrecional que la habilita a decidir si aplicará la multa: i) conforme a los límites dispuestos en los artículos 27 y 28 , o ii) en hasta un 30\% del valor de la emisión u operación irregular. Decisión que, en términos generales, estará supeditada a la magnitud de la infracción cometida y a las finalidades de prevención general o especial que persiga la SVS, de lo cual se deberá dejar constancia en la parte considerativa de la respetiva resolución.

Luego, para determinar la multa específica, en el primer caso, la autoridad deberá contrastar las circunstancias del caso concreto con alguna de las directrices señaladas en los artículos 27 y 28, a saber: la gravedad y las consecuencias del hecho, la capacidad económica del infractor y si este hubiere cometido otras infracciones de cualquier naturaleza en los últimos 24 meses. Por su parte, si opta por el segundo de los supuestos, la autoridad, en principio, carecería de criterios legales de determinación de sanción, toda vez que para su aplicación el legislador omitió hacer referencia a los parámetros que se deben revisar para cuantificar la multa.

En otros términos, el legislador configuró una doble facultad discrecional de diversa intensidad. La primera de ellas importa una potestad discrecional de carácter restringida o débil, esto es, los elementos reglados que la constituyen son cuantiosos: establece la potestad (de tipo represivo o sancionador), la finalidad pública (evitar la infracción de normas económico-financieras y del mercado de valores), fija el tipo de sanción (multa), el órgano competente para aplicarla (la SVS), el máximo importe de la sanción (15.000 UF, la que puede aumentar en caso de reiteración) y algunos límites que se deben observar en su aplicación (la gravedad de hecho, las consecuencias de la infracción, la capacidad económica del infractor y la reiteración). Tratándose de la segunda de las alternativas, el legislador

10 Al hacer sinónimos arbitrariedad y discrecionalidad, traslada a esta última a un ámbito negativo. 
también ha configurado un poder discrecional, esta vez un poco más fuerte o amplio, con diversos elementos reglados: la potestad (de tipo represivo o sancionador), la finalidad pública (evitar la infracción de normas económico-financieras y del mercado de valores), fija el tipo de sanción (multa), su base de cálculo (el valor de la emisión u operación irregular ${ }^{11}$ ), el máximo importe de la sanción (30\% desde la base de cálculo), el órgano competente para aplicarla (la SVS) y un criterio de aplicación (la reiteración).

Como se puede advertir, en este caso el legislador sí ha entregado criterios mínimos para que la autoridad pueda determinar el quantum de la sanción de multa, no siendo efectivo en definitiva que el precepto carece de ellos. Cuestión distinta es que dicho establecimiento no sea suficiente, a juicio del Tribunal, atendido el escaso número de parámetros proporcionados, con lo cual cabe preguntarse cuál sería el "estándar constitucional" que en opinión del Tribunal sería ideal para que el considerar acorde con la Carta Fundamental el establecimiento de dichos criterios ${ }^{12}$.

\section{SOBRE LA INEXISTENCIA DE “CRITERIOS LEGALES” PARA LA DETERMINACIÓN DE SANCIONES}

En el caso en comento el Tribunal otorga un alto estándar a los criterios establecidos por el legislador para determinar sanciones administrativas, elevando inclusive su existencia a un requisito esencial de la ley.

En este sentido, si bien el establecimiento de criterios por parte del legislador opera como límite a la discrecionalidad del órgano sancionador, sin eliminar la flexibilidad que amerita la adopción de una decisión esencialmente particular ${ }^{13}$, ello no excluye la existencia de otros límites, como los de orden administrativo (autolimitación) o judicial (aquella que realiza el juez al controlar el acto administrativo que impone la sanción).

El legislador al configurar un sistema represivo puede otorgar a la Administración un nivel de discrecionalidad más o menos fuerte. De tal modo, puede entregar un vasto catálogo de parámetros para determinar la intensidad de la sanción aplicable o bien, puede proporcionar algunos elementos mínimos para graduar la sanción ${ }^{14}$.

\footnotetext{
11 Se trata de un hecho objetivo que se construye a partir de lo dispuesto en el propio artículo 29 del DECRETO LEY $\mathrm{N}^{\circ} 3.538$, de 1980, y en los artículos 52, inciso primero (Es contrario a la presente ley efectuar transacciones en valores con el objeto de estabilizar, fijar o hacer variar artificialmente los precios) y 53 , inciso segundo (Ninguna persona podrá efectuar transacciones o inducir o intentar inducir a la compra o venta de valores, regidos o no por esta ley, por medio de cualquier acto, práctica, mecanismo o artificio engañoso o fraudulento), ambos de la LEY $\mathrm{N}^{\circ}$ 18.045, Ley del Mercado de Valores.

12 Recientemente se ha aprobado la Ley No 21.000, que crea la Comisión para el Mercado Financiero, texto que reemplaza el actual DL $\mathrm{N}^{\circ} 3538$. Dicha norma reformula el aludido artículo 29, incorporándolo en los numerales 2 letras b) de los artículos 36 y 37, respectivamente, en términos similares a la legislación derogada. Sin embargo, agrega, en el artículo 38, para la determinación del rango y del monto específico de las multas a las que se refieren dichos artículos, un conjunto de circunstancias que la Comisión deberá procurar para que su aplicación resulte óptima para el cumplimiento de los fines que la ley le encomienda.

13 Fiscalía Nacional Económica con Servicios Pullman Bus Costa Central S.A. y otros (2014). Artículo 26, literal c) del Decreto Ley No 211, de 1973, en relación con lo dispuesto en el inciso $1^{\circ}$ del artículo $3^{\circ}$ del mismo cuerpo legal, Rol No 2658-14. En particular, véase el considerando 8.

$14 \mathrm{Al}$ efecto, en Guard SerVice Seguridad S.A. con Inspección Provincial del Trabajo de Valparaíso (2015). Artículos 505, 505 bis y 506 del Código del Trabajo, Rol No 2671-14. En particular, véase la prevención del Ministro Juan José Romero Guzmán, pp. 30 y ss.
} 
En la situación en análisis, el legislador dispuso que tratándose de la aplicación de una sanción de multa la autoridad tiene dos opciones: a) puede aplicar los criterios dispuestos en los artículos 27 y 28 del referido Decreto Ley; o, b) puede utilizar como base el valor de la emisión u operación irregular aumentada hasta en un $30 \%$.

Las interrogantes que surgen al respecto son si la situación prevista en la letra b) es constitucionalmente válida para determinar una sanción administrativa, si la discrecionalidad en ella contenida permite orientar la potestad represiva y si es preciso la configuración de criterios expresos para su conformidad con la Carta Fundamental.

Es posible responder positivamente a las dos primeras interrogantes y no a la última de ellas. Ello por cuanto, como se ha indicado, el artículo recurrido cuenta con ciertos elementos reglados que le permiten a la SVS ponderar las circunstancias específicas del caso concreto y aplicar la sanción que conforme a ello corresponda (como la reiteración o el tratase de una operación irregular), con lo cual cumple la exigencia de entregar parámetros (aunque sean mínimos) que orienten la labor de la autoridad para determinar la intensidad de la sanción. Por lo demás, es perfectamente plausible que la autoridad, una vez analizados los hechos, pueda recurrir a criterios dispuestos en otros preceptos de su ley orgánica para establecer el quantum de la sanción.

\section{Sobre El IMPORTE MÁXIMO DE LAS MULTAS ADMINISTRATIVAS}

Como se sabe, no existe una regulación general que establezca el monto máximo que deben observar las multas administrativas ni mucho menos respecto del intervalo dentro cual pueden oscilar ${ }^{15}$. Al efecto, son las leyes especiales las que los establecen conforme a las singularidades de cada sector ${ }^{16}$. Así las cosas, las fórmulas de determinación de las sanciones pecuniarias se encuentran recogidas en forma sumamente flexible y pueden oscilar entre: diversas unidades de medida (UF, UTM, UTA, sueldos vitales, etc.), fluctuación entre parámetros máximos y mínimos, fijación proporcional al monto del ilícito cometido o la ganancia obtenida ${ }^{17}$, entre otros.

En tal sentido, no hay más restricciones constitucionales para el legislador que las derivadas de los principios de legalidad, tipicidad y proporcionalidad. Por su parte, la Administración debe observar las reglas legales predispuestas (criterios) y el anotado principio de proporcionalidad, lo que en definitiva le permitirá adecuar la sanción a la infracción y al infractor, lo que por lo demás facilitará el control judicial posterior.

En el caso concreto, si bien los elementos de valoración de la multa están estrechamente vinculados con la entidad de la emisión u operación irregular, ello no convierte a la disposición en inconstitucional, puesto que la exigencia de previa determinación normativa se cumple en la medida en que las sociedades anónimas o personas o entidades diversas de aquellas, sujetas a la fiscalización de la SVS puedan o deban ser conscientes de que cuanto

15 Código Penal con excepciones.

16 Rebollo (2010) pp. 985 y ss.

17 En materia de libre competencia, es usual que se establezcan multas vinculadas a las ganancias financieras de las empresas infractoras, ello debido principalmente a la posibilidad de que una multa establecida en términos fijos pueda no ser suficiente para disuadir la comisión de futuros ilícitos, véase OCDE (2002) p. 10 y RoMERO (2011) pp. 522 y 523. 
mayor sea el importe de la actividad prohibida, mayor será el quantum de la sanción pecuniaria, todo ello sujeto a los límites máximos que fija el propio artículo 29.

En definitiva, la fijación discrecional de sanciones se debe ejercitar respetando los elementos reglados dispuestos en la norma, complementando dicha decisión con los principios generales del Derecho, y, entre ellos, el de igualdad y el de proporcionalidad, todo lo cual deberá ser dispuesto en la resolución respectiva con una expresa motivación de las circunstancias que llevan a fijar la intensidad de las sanciones ${ }^{18}$.

\section{El PROBLEMA DE FONDO: LA AUSENCIA DE MOTIVOS}

En definitiva, pareciera ser que el conflicto va más allá de la discrecionalidad amplia entregada a la Superintendencia para fijar la sanción de multa, sino que radica, más bien, en la deficiente fundamentación de los motivos o razones que sustentaron el quantum de la decisión de la autoridad.

Esto traslada el asunto a un nivel de "criterios judiciales" conforme a los cuales los jueces del fondo deberán controlar que la autoridad, en el uso de la discrecionalidad que le ha sido otorgada, haya explicitado de manera clara, precisa y coherente los supuestos fácticos que la llevaron a aplicar la sanción específica, lo que al parecer no habría ocurrido en el caso en comento al precisar que “(...) no observa la razón concreta de por qué se opta por un determinado monto pecuniario, lo que se constata, además, del tenor literal de la disposición legal, que no ha fijado baremos precisos para arribar al "quantum" de la multa, la que en definitiva queda entregada al arbitrio de la autoridad administrativa;" (considerando 46, parte final).

\section{SOBRE LA NECESIDAD-ESENCIALIDAD DE LOS "CRITERIOS LEGALES" PARA LA DETERMINACIÓN DE SANCIONES}

Para que la autoridad ejerza su poder punitivo, la atribución debe estar establecida en una norma de rango legal (reserva legal) y, además, la conducta infraccional y la sanción deben estar dispuestas previamente en una ley (tipicidad) ${ }^{19}$. En consecuencia, tanto la potestad sancionadora como su ejercicio son atribuciones reguladas por ley ${ }^{20}$. Sin perjuicio de ello, al analizar diversas disposiciones sancionatorias, es posible advertir que la potestad represiva habitualmente se encuentra revestida de diversos márgenes de discrecionalidad.

En efecto, el legislador puede configurar normativamente los contornos del poder punitivo que entregará a la Administración, en la medida que no establezca sanciones pri-

\footnotetext{
$18 \quad$ Nieto (2012) pp. 519 y ss.

19 Además, pueden concurrir otros elementos reglados como, por ejemplo: el tiempo u ocasión de ejercicio de la potestad, forma de ejercicio, fondo parcialmente reglado (v. gr. la facultad de elección de personas dentro de ciertas categorías, determinación discrecional de un quantum pero dentro de determinadas magnitudes, etc.), en García de Enterría y Fernández (2011) Tomo I, p. 479.

20 Sobre el establecimiento normativo de la potestad sancionadora Nieto ha señalado que: "En virtud del principio de juridicidad (prescindiendo ahora de su variante concreta de legalidad) las actividades sancionadoras individualizadas deben estar previstas previamente en una norma. Como consecuencia del principio constitucional de reserva legal se ha privado a la Administración de esta facultad de establecimiento, cuyo ejercicio no es originario sino derivado de la ley y, por su manifestación reglamentaria, (...)”, en NieTo (2012) p. 99.
} 
vativas de libertad y respete el principio de proporcionalidad entre la limitación del derecho fundamental y el objetivo constitucionalmente válido que se busca perseguir ${ }^{21}$.

Sin embargo, en la mayoría de los casos, el legislador no logra desarrollar una regulación sancionatoria exhaustiva de las formas en que deberá ser ejercida esta potestad por la autoridad ante diversos supuestos fácticos, frente a lo cual ha adoptado fórmulas normativas que entregan ciertos márgenes de discrecionalidad a la Administración. En este sentido, en la etapa final de un procedimiento sancionatorio es posible advertir, con mayor claridad y habitualidad, los poderes discrecionales que tiene la Administración, dado que es allí donde la autoridad decide el tipo de sanción que aplicará y su intensidad.

Así, por ejemplo, en materia de valores y seguros, existen una serie de preceptos que contienen expresiones tales como: "la superintendencia podrá aplicar las sanciones que estime pertinentes" 22 , "la autoridad podrá fijar el monto de la multa a su elección"23, entre otros ejemplos. Tales enunciados son una manifestación de la señalada discrecionalidad ${ }^{24}$.

Ahora bien, una de las principales incertidumbres que queda después de este fallo, es si la inexistencia de criterios legales, esto es, de criterios determinación de sanciones administrativa dispuestos por el legislador, puede significar un impedimento para que la autoridad aplique sanciones. Lo cual resulta complejo y problemático atendido el hecho de que diversas regulaciones administrativas sancionadoras no cuentan con un catálogo de criterios (v. gr. el orden represivo sanitario).

Bajo tal predicamento, cabe destacar que ante la falta de los mismos -o aun contando con ellos- los órganos podrían autolimitar la potestad represiva conferida por el legislador mediante la dictación de un acto administrativo que oriente su actividad sancionadora, con en los hechos lo han realizado algunos órganos ${ }^{25}$.

21 Cordero (2014) p. 54.

22 Artículo 28 inciso final del Decreto Ley No 3.538, de 1980.

23 Artículo 29 del Decreto Ley No 3.538, de 1980.

24 Sobre el uso de la expresión "podrá” el Tribunal Federal Alemán ha señalado que cuando el "legislador expide la autorización para intervenir bajo la forma de una cláusula facultativa ("podrá”), estará colocando a disposición de la administración esa intervención como un instrumento con el cual esta puede desempeñar las funciones que le han sido atribuidas. Sin embargo, no obliga a la administración a hacer uso de ella en todos los casos en que se den estas circunstancias de hecho, ya que, desde el punto de vista del legislador, la administración no requiere en todos los casos del empleo de estos medios en contra del particular. Por tanto, limita la intervención y deja a la discrecionalidad de la administración que, atendiendo a las circunstancias y respetando el principio de igualdad que informa toda aplicación de la ley, la decisión de hacer uso de las posibilidades de intervención, claramente delimitadas que el legislador ha puesto a su disposición, lo que además se encuentra de conformidad con el principio del Estado de Derecho", en causa Rol 2 BvL 10/56, de 3 de febrero de 1959, resumen en español y la sentencia en alemán disponibles en: http://estudios.tribunalconstitucional.cl/jurisprudencia-comparada, última visita el 13 de junio de 2016.

25 Algunos ejemplos de esta autolimitación los proporcionan la Superintendencia del Medio Ambiente (resolución exenta No 1.002, de 2015 que fijó las "Bases metodológicas para la determinación de sanciones ambientales); Superintendencia de Educación (Oficio N 182, de 2014, sobre "Procesos Administrativos Sancionatorios y Aplicación de Sanciones”); Servicio de Impuestos Internos (Circular N 1, de 2004); Dirección del Trabajo (Circulares Nos. 18, de 2010 y 93, de 2011, las cuales establecen instrucciones sobre procedimientos de fiscalización. Junto con ello, cuenta con un documento denominado "Tipificador de hechos infraccionales y pauta para aplicar multas administrativas”); Instituto de Salud Pública (resolución exenta No 1.787, de 2012, estableció un catálogo de criterios a considerar al momento de determinar las sanciones a aplicar en los suma- 
Se trata de instrumentos destinados a explicitar, detallar y describir un conjunto de paramentos que, de manera general, la autoridad tendrá en consideración para aplicar la medida represiva, lo cual proporciona cierta certeza y seguridad al eventual infractor.

Asimismo, frente a la ausencia de un acto de esta índole, vía motivación, la autoridad administrativa puede -y debe- explicitar en la resolución que aplica la sanción respectiva, cuáles fueron los parámetros que, dadas las circunstancias concretas de la infracción y del infractor, aplicó en el proceso de fijación de la misma.

Por último, será el propio juez quien en el proceso de revisión judicial, al advertir la ausencia de criterios suficientes de fundamentación en la decisión administrativa, podrá incorporar parámetros que limiten la discrecionalidad ejercida por la Administración, incorporando estándares como la gravedad de la infracción, el daño causado por la misma, la colaboración en el esclarecimiento de los hechos, la capacidad económica del infractor, el porcentaje de usuarios afectados, la irreprochable conducta anterior, beneficio económico obtenido con el ilícito, entre otros.

\section{CONCLUSIONES}

La determinación de las sanciones administrativas exige un margen de discrecionalidad, cuyo ejercicio estará siempre sujeto a diversos criterios de aplicación de diverso orden: legal, administrativo o judicial, ello con el objeto de evitar arbitrariedades y/o la afectación a ciertos principios constitucionales, como la proporcionalidad.

Lo anterior, por cuanto la adopción de una medida sancionadora escapa al empleo de procesos automatizados, en los cuales precisada la infracción se establezca ipso facto su consecuencia represiva. De este modo, coincidiendo con lo señalado por Alejandro Nieto, la toma de una decisión sancionadora es un complejo proceso humano, siendo la fase de adjudicación de la sanción, donde la discrecionalidad alcanza su máxima expresión, puesto que solo está limitada por parámetros legalmente predeterminados y por el uso prudente y razonado de la proporcionalidad.

Entender la legalidad en términos estrictos importaría una grave crisis al sistema sancionatorio, por lo que la configuración de la potestad mediante una fórmula híbrida que conjugue elementos reglados y discrecionales sumados a la revisión judicial posterior de los actos sancionatorios, evita un colapso normativo y permite su funcionamiento.

Es evidente percibir que en esta ocasión el Tribunal Constitucional no comparte las ventajas de la aludida fórmula; ello pese a que desde hace más de 20 años a la fecha sostiene la necesaria matización de los principios penales del orden constitucional al Derecho Administrativo Sancionador, doctrina que atenúa los estrictos parámetros dispuestos para dicha disciplina.

Por tanto, y al contrario de la decisión sostenida por el Tribunal Constitucional, la configuración de un margen de apreciación discrecional en la determinación de sanciones es de trascendental importancia no solo para la autoridad administrativa sino que también

rios sanitarios); Superintendencia de Valores y Seguros (resolución exenta No 271, de 2015, aplicable solo a las empresas de menor tamaño). 
para el juez revisor, por cuanto permite que se puedan adaptar las normas a las condiciones específicas del supuesto fáctico y, en su caso, circunscribirlas a infracciones no acabadamente reguladas, sin necesidad de acudir a la analogía.

Finalmente, surgen como límites implícitos a esta potestad la proporcionalidad y su establecimiento en armonía con un mínimo de elementos reglados (la atribución, el órgano competente, la infracción y la intensidad de la sanción, sean en montos mínimos y máximos o determinables conforme a una base de cálculo).

\section{BIBLIOGRAFÍA CITADA}

Aróstica Maldonado, Iván (1987a): "Algunos problemas del Derecho Administrativo Penal”, Revista de Derecho Universidad de Concepción, No 182: pp. 71-81.

Aróstica Maldonado, Iván (1987b): "El Derecho Administrativo Sancionador y la proporcionalidad de los actos administrativos (un asunto de justicia distributiva)", Revista de Derecho y Jurisprudencia y Gaceta de los Tribunales, No 3, Tomo 84: pp. 109-125.

Aróstica Maldonado, Iván (1988): "Algunos problemas del Derecho Administrativo Penal", Revista de Derecho y Jurisprudencia y Gaceta de los Tribunales, Tomo 85, No 1: pp. 41-51.

Cordero Quinzacara, Eduardo (2014): "Los principios y reglas comunes al procedimiento administrativo sancionador", en Arancibia Mattar, Jaime y Alarcón Jaña, Pablo (Coords.), Sanciones Administrativas (Santiago, Thomson Reuters - La Ley) pp. 189215.

García de Enterría, Eduardo; Fernández, Tomás-Ramón (2011): Curso de Derecho Administrativo, Tomo I (Madrid, Civitas - Thomson Reuters, decimoquinta edición).

Nieto García, Alejandro (2012): Derecho Administrativo Sancionador (Madrid, Tecnos, quinta edición totalmente reformada).

OCDE (2002): Report on the nature and impact of hard core carteles and sanctions againist cartels under national compettition laws. Disponible en: http://www.oecd.org/competition/cartels/2081831.pdf. Fecha de consulta: 3 de noviembre de 2016.

Rebollo Puig, Manuel (2010): "Sanciones pecuniarias", en Lozano Cutanda, Blanca (Directora), Diccionario de sanciones administrativas (Madrid, Iustel) pp. 985-1000.

Román Cordero, Cristian (2010): "El castigo en el Derecho Administrativo", Revista de Derecho y Humanidades, No 16, vol. 1: pp. 155-171.

Romero, Juan José (2011): "Enforcement, sanciones y multas en el sistema de libre competencia chileno", en La libre competencia en el Chile del bicentenario, Tribunal de Defensa de la Libre Competencia (Santiago, Thomson Reuters) pp. 503-537.

Soto Kloss, Eduardo (1979/1980): "Derecho Administrativo Penal. Notas para el estudio de la potestad sancionadora de la Administración”, Boletín de Investigaciones, Facultad de Derecho de la Pontificia Universidad Católica de Chile, No 44-45: pp. 95-103. 


\section{NORMAS CITADAS}

LEy Nº 18.045 (22/10/1981), Ley del Mercado de Valores.

LeY No 20.417 (26/01/2010), Crea el Ministerio, el Servicio de Evaluación Ambiental y la Superintendencia de Medio Ambiente.

LeY No 21.000 (23/02/2017), que crea la Comisión para el Mercado Financiero.

Decreto Ley No 3.538 (23/12/1980), que crea la Superintendencia de Valores y Seguros.

Código Penal (12/11/1874).

\section{JURISPRUDENCIA CITADA}

\section{Judicial}

Constructora Isla Grande Limitada con SEREMI de Salud de la Región MEtropolitana (2015): Corte Suprema, 19 de octubre de 2015 (reclamación de multa administrativa), en Legal Publisher, Código de búsqueda CL/JUR/6278/2015; 109778, Fecha de consulta 8 de noviembre de 2016.

Cúneo y otros con Superintendencia de VAlores y Seguros (2015): Corte Suprema, 3 de diciembre de 2015 (reclamación de multa administrativa), en Legal Publisher, Código de búsqueda CL/JUR/7635/2015; 113560, Fecha de consulta 8 de noviembre de 2016.

Aguas Araucanía S.A. con Superintendencia de Servicios Sanitarios (2016): Corte Suprema, 2 de agosto de 2016 (reclamación de multa administrativa), en Legal Publisher, Código de búsqueda CL/JUR/5446/2016; 132091_CL, Fecha de consulta 8 de noviembre de 2016.

Farah Con Superintendencia de VAlores y Seguros (2016): Corte Suprema, 24 de agosto de 2016 (reclamación de multa administrativa), en Legal Publisher, Código de búsqueda CL/JUR/5933/2016; 133918_CL, Fecha de consulta 8 de noviembre de 2016.

\section{Constitucional}

Alberto Le Blanc Matthei con Superintendencia de Valores y Seguros (2018): Tribunal Constitucional, 7 de mayo de 2018 (requerimiento de inaplicabilidad por inconstitucionalidad), Rol No3542-2017.

Fiscalía Nacional Económica con Servicios Pullman Bus Costa Central S.A. y otros (2014): Tribunal Constitucional, 9 de octubre de 2014 (requerimiento de inaplicabilidad por inconstitucionalidad), Rol No 2658-14.

Guard Service Seguridad S.A. con Inspección Provincial del Trabajo de Valparaíso (2015): Tribunal Constitucional, 1 de octubre de 2015 (requerimiento de inaplicabilidad por inconstitucionalidad), Rol No 2671-14. 
Honorable Camara de Diputados (1996): Tribunal Constitucional, 26 de agosto de 1996 (control de constitucionalidad del proyecto de ley que modifica la ley No 4.601, Ley de Caza, a fin de proteger la fauna), Rol No 244-96.

Julio Ponce Lerou con Superintendencia de Valores y Seguros (2018): Tribunal Constitucional, 24 de mayo de 2018 (requerimiento de inaplicabilidad por inconstitucionalidad), Rol N³236-2016.

LarRaÍn Vial S.A. con Superintendencia de VALORES y Seguros (2018): Tribunal Constitucional, 7 de mayo de 2018 (requerimiento de inaplicabilidad por inconstitucionalidad), Rol N³575-2017.

LEONIDAs Vial ECHEVERRÍa con Superintendencia de VALORES Y SEgUROS (2018): Tribunal Constitucional, 7 de mayo de 2018 (requerimiento de inaplicabilidad por inconstitucionalidad), Rol N³684-2017.

Manuel Bulnes Muzard y Felipe ERrázuriz Amenábar con Superintendencia de Valores y SEGUROS (2017): Tribunal Constitucional, 14 de noviembre de 2017 (requerimiento de inaplicabilidad por inconstitucionalidad), Rol N 3014-2016.

Roberto Guzmán LyON con Superintendencia de VALORES y SEGUROS (2016): Tribunal Constitucional, 29 de septiembre de 2016 (requerimiento de inaplicabilidad por inconstitucionalidad), Rol No 2922-2015.

\section{Administrativa}

Dictamen de la Contraloría General de la República (2014): No 16.157, de 4 de marzo de 2014

Dictamen de la Contraloría General de la República (2013): No 60.341, de 23 de septiembre de 2013.

Dictamen de la Contraloría General de la República (2013): No 13.790, de 28 de febrero de 2013.

Dictamen de la Contraloría GENERAL DE LA República (2011): № 63.697, de 7 de octubre de 2011.

Dictamen de la Contraloría General de la República (2011): No 22.483, de 13 de abril de 2011.

Dictamen de la Contraloría General de la República (2008): № 34.407, de 24 de julio de 2008.

Dictamen de la Contraloría General de la República (2005): No 31.239, de 5 de julio de 2005.

Dictamen de la Contraloría General de la República (2005): No 14.571, de 22 de marzo de 2015 .

\section{Extranjera}

Rol 2 BvL 10/56, de 3 de febrero de 1959, resumen en español y la sentencia en alemán disponibles en: http://estudios.tribunalconstitucional.cl/jurisprudencia-comparada, Fecha de consulta 8 de noviembre de 2016. 